\title{
A randomized, controlled, crossover trial of oral midazolam and hydroxyzine for pediatric dental sedation
}

\section{Sedação com midazolam e hidroxizina por via oral em Odontopediatria: ensaio clínico randomizado, controlado e cruzado}

\author{
Alessandra Rodrigues de Almeida Lima* \\ Luciane Ribeiro de Rezende Sucasas da Costa** \\ Paulo Sérgio Sucasas da Costa***
}

\begin{abstract}
The effectiveness of oral midazolam in pediatric dentistry is controversial. This randomized, controlled, crossover, double blind clinical trial was conducted in order to study the effect of midazolam, used either alone or in association with hydroxyzine, during child dental treatment. Thirty seven dental sedation sessions were carried out on 11 ASA I uncooperative children less than five years-old. In each appointment children were randomly assigned to groups: P - placebo, M - midazolam $(1.0 \mathrm{mg} / \mathrm{kg})$, or $\mathrm{MH}$ - midazolam $(0.75 \mathrm{mg} / \mathrm{kg})$ plus hydroxyzine $(2.0 \mathrm{mg} / \mathrm{kg})$. Vital signs (blood pressure, breathing rate, pulse and oxygen saturation) and behavior parameters (consciousness, crying, movement, overall behavior) were evaluated every 15 minutes. Friedman and Wilcoxon statistical tests were used to compare groups and different moments in the same group. Normal values of vital signs were usually registered. Heart rate increased in groups $\mathrm{P}$ and $\mathrm{M}$ as the session went on. Group $\mathrm{M}$ presented less crying and movement at the first 15 minutes of treatment. Group MH caused more drowsiness at the beginning of the session. Overall behavior was better in group $\mathrm{M}$ than in groups $\mathrm{P}$ or $\mathrm{MH}$. Group $\mathrm{M}$ produced effective sedation in $77 \%$ of the cases, and group $\mathrm{MH}$ did so in $30.8 \%$. It was concluded that midazolam was effective and safe, and its association with hydroxyzine did not lead to additional advantages in pediatric dental sedation.
\end{abstract}

DESCRIPTORS: Conscious sedation; Hydroxyzine; Pediatric dentistry.

RESUMO: Há controvérsias quanto aos benefícios do midazolam na sedação de crianças durante a atenção odontológica. Conduziu-se um ensaio clínico controlado, cruzado e duplo-cego para comparar o efeito sedativo em Odontopediatria da administração oral do midazolam, associado ou não à hidroxizina. Trinta e sete sessões foram realizadas em 11 crianças menores de cinco anos, ASA I. Em cada atendimento, os pacientes receberam aleatoriamente o medicamento conforme os grupos: $\mathrm{P}$ - placebo, $\mathrm{M}$ - midazolam $(1,0 \mathrm{mg} / \mathrm{kg}) ; \mathrm{MH}$ - midazolam $(0,75 \mathrm{mg} / \mathrm{kg})$ associado à hidroxizina $(2,0 \mathrm{mg} / \mathrm{kg})$. Os sinais vitais (pressão arterial, freqüência respiratória, pulso e saturação de oxigênio) e os parâmetros comportamentais (consciência, choro, movimento, comportamento geral) foram avaliados a cada 15 minutos. As comparações entre grupos e entre momentos de atendimento num mesmo grupo foram estabelecidas estatisticamente através dos testes Friedman e Wilcoxon. Os grupos P, M e MH não diferiram quanto aos sinais vitais, os quais se mantiveram dentro de valores aceitáveis. A freqüência cardiaca aumentou nos grupos $\mathrm{P}$ e $\mathrm{M}$ com o transcorrer da sessão. $\mathrm{O}$ grupo $\mathrm{M}$ esteve associado a menos choro e movimento nos primeiros 15 minutos de tratamento. O grupo MH apresentou mais sonolência no início da sessão. O comportamento geral foi melhor em M do que em P e MH. M produziu sedação efetiva em $77 \%$ dos casos, e MH em 30,8\%. Concluiu-se que o midazolam foi efetivo e seguro, e que sua associação à hidroxizina não repercutiu em vantagens adicionais na sedação odontopediátrica.

DESCRITORES: Sedação consciente; Hidroxizina; Odontopediatria.

\section{INTRODUCTION}

There are still a fair number of children for whom the conventional, psychological approach alone is not enough to provide quality dental care. For them, pharmacological intervention becomes a strong alternative.
One of the possible sedative drugs in dentistry is midazolam, a short-acting benzodiazepine which can provide safe and effective sedation before surgical procedures ${ }^{18}$, with anterograde amnesia promotion ${ }^{12}$. When used with other central nervous systems depressants, midazolam can produce adverse respiratory events. Its commonly re-

${ }^{*}$ MSc Student, Health Sciences Program; **PhD, Adjunct Professor, Discipline of Pediatric Dentistry, School of Dentistry; ***PhD, Adjunct Professor, Discipline of Pediatrics, School of Medicine - Federal University of Goiás. 
Lima ARA, Costa LRRS, Costa PSS. A randomized, controlled, crossover trial of oral midazolam and hydroxyzine for pediatric dental sedation. Pesqui Odontol Bras 2003;17(3):206-11

ported effective oral doses range from $0.25-1.0 \mathrm{mg} / \mathrm{kg}$ in children (maximum $20 \mathrm{mg}$ ). It is quickly absorbed after administration via the oral route, can take effect within 15 minutes, reaching a peak in 30 minutes $^{3}$, and lasts from 20 to 90 minutes $^{7}$. A number of studies have employed enteral midazolam for pediatric dental sedation ${ }^{6,14,15,17,24,26}$, and even as premedication before nitrous oxide/oxygen analgesia ${ }^{5,20,23}$, most of them being retrospective studies.

However, the usefulness of midazolam alone is limited to short-duration procedures, and controlled data are needed to identify safe oral conscious regimens which permit longer duration procedures ${ }^{19}$.

Wilson ${ }^{25}$ suggested various sedation protocols for dental treatment, including the association of hydroxyzine $(1-2 \mathrm{mg} / \mathrm{kg})$ with midazolam $(0.3-0.75 \mathrm{mg} / \mathrm{kg})$. Hydroxyzine is a long-acting $(6$ to 24 hours) anti-histaminic, $\mathrm{H} 1$ antagonist, which acts as a central nervous system depressant, showing itself to be a weak anxiolytic drug ${ }^{10,11,16,21}$.

To date, only a few trials have reported the effects of midazolam combined with hydroxyzine in dental practice ${ }^{23}$. The objective of this paper is to compare the efficacy and safety of midazolam, either alone, or in association with hydroxyzine, in dental treatments. The hypothesis to be tested is whether the addition of hydroxyzine would improve the patient's behavior without affecting vital signs, thus enabling longer periods of moderate or conscious sedation.

\section{MATERIAL AND METHODS}

The protocol was approved by the Federal University of Goiás (UFG) Ethical Committee; written informed consent was obtained from the parents of each child, and all the procedures followed were in accordance with Resolution 196/96 of Health State Department, Brazil.

Patients treated at the dental clinic of the School of Dentistry/UFG from January 2001 until December 2002 were selected, providing they were up to 60 months old, ASA (American Society of Anesthesiologists) I class, were uncooperative after four sessions of behavior management, and needed at least three routine restorative visits. Exclusion criteria were tonsil hypertrophy, history of allergies, drooling or nocturnal snoring.

Children fasted for a minimum of six hours for solids and two hours for clear liquids. After the physical examination, the pediatrician administered the medication orally, in a random manner, according to the groups: $\mathrm{P}$ (placebo), $\mathrm{M}$ (midazolam $1.0 \mathrm{mg} / \mathrm{kg}$ ) or $\mathrm{MH}$ (midazolam $0.75 \mathrm{mg} / \mathrm{kg}$ and hydroxyzine $2.0 \mathrm{mg} / \mathrm{kg}$ ). The drugs (magistral formulation, Pharmacia Artesanal, Goiânia, Brazil) were prepared by a pharmacist and were given in a suspension of $1 \mathrm{ml} / \mathrm{kg}$. In order to prevent sedative identification, medicine bottles received codes known only to the pediatrician. Emergency drugs and equipment were available at all times.

The child and his/her parents rested in a calm place for 30 minutes, after which the dental treatment began. Local anesthesia was obtained when indicated, using $2 \%$ xylocaine with 1:100,000 epinephrine. When rubber dam use was not possible due to insufficient dental structure, a mouth prop was inserted together with cotton rolls and a suction device. Parents were allowed to stay with their child during the dental appointment, if they wanted. Physical restraint was applied in cases where movement interfered with the completion of treatment. Following the appointment, written post-care instructions were reviewed with parents and the child was discharged when the appropriate discharge criteria were met.

The course of sedation was observed and noted by an examiner who was blind to the sedative, during the medical examination (baseline), and every 15 minutes. The patients' vital signs which were evaluated were breathing rate (counting the thorax-abdominal movements per minute); heart rate and oxygen saturation (as shown on the display of an Ohmeda 3800 pulse oximeter (Datex - Ohmeda, Helsink, Finland), whose sensor was placed on the patient's big toe); and blood pressure (checked with an adult-size cuff on the child's thigh).

Behavior evaluation was based on a scale proposed by Houpt et al. ${ }^{13}$, which establishes the following scores: sleep - 1 (awake), 2 (drowsy), 3 (asleep); movement - 1 (violent), 2 (continuous), 3 (controllable), 4 (no movement); crying - 1 (hysterical), 2 (continuous), 3 (intermittent), 4 (no crying); overall behavior - 1 (aborted), 2 (poor), 3 (regular), 4 (good), 5 (very good) and 6 (excellent). Sedation was considered successful when overall behavior scores of 5 or 6 were achieved with no adverse reactions in vital signs during the entire procedure. A score of 4 (good) was not included because it represents "some difficulty, but all treatment performed" ${ }^{13}$.

Data were compared using a Friedman non-parametric statistical test with Winstat software (R. Fitch Software, USA), with a significance index of 0.05. Equivalency was verified between groups $\mathrm{P}, \mathrm{M}$ and $\mathrm{MH}$ with regards to the parame- 
Lima ARA, Costa LRRS, Costa PSS. A randomized, controlled, crossover trial of oral midazolam and hydroxyzine for pediatric dental sedation. Pesqui Odontol Bras 2003;17(3):206-11

ters which were observed and, within each group, the figures obtained at each evaluation (15 minutes) and at baseline. When statistically significant differences were detected, a Wilcoxon rank sum test was used in order to select specific differences among groups.

\section{RESULTS}

Thirty seven dental sessions were conducted on 11 patients, three males and eight females. Their mean age was 40 months (range 20 to 59 months). One child needed five sessions to complete the dental treatment plan; four children required four visits, while two came for two visits. Dental sessions lasted from 27 to 95 minutes; the means for each treatment were $51.6(\mathrm{P}), 55.2(\mathrm{M})$ and 47.3 $(\mathrm{MH})$ minutes $(\mathrm{p}=0.839)$.

Statistically significant differences in the effect of medications on breathing rate, heart rate, blood
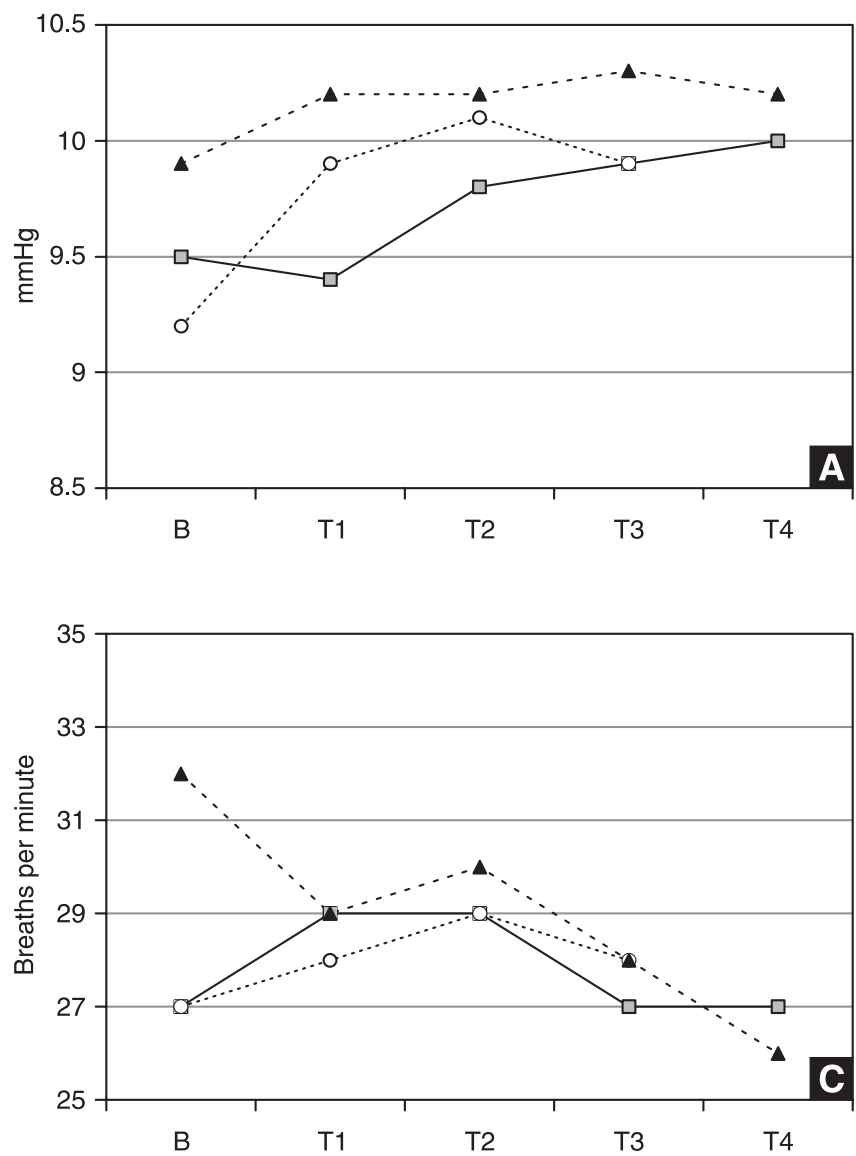

pressure and oxygen saturation showed by $\mathrm{P}, \mathrm{M}$ and $\mathrm{MH}$ comparisons were not found. The average values for these parameters are presented in Graph 1.

Nevertheless, when we considered each group individually, there were significantly different changes in the heart rate of groups $P$ and $M$ $(p=0.000)$. A crescent heart rate was observed during the dental treatment, but in $\mathrm{M}$ the evaluation at the beginning of the session was similar to that of baseline. Occasionally all groups had values as high as 160 to 198 beats per minute.

Oxygen saturation values were above $90 \%$ in all cases, and there were no differences between groups $\mathrm{P}, \mathrm{M}$ and $\mathrm{MH}$, or between treatment periods and baseline values in each group.

When the three groups where compared concerning behavior parameters, whose mean values are showed in Graph 2, group MH presented more
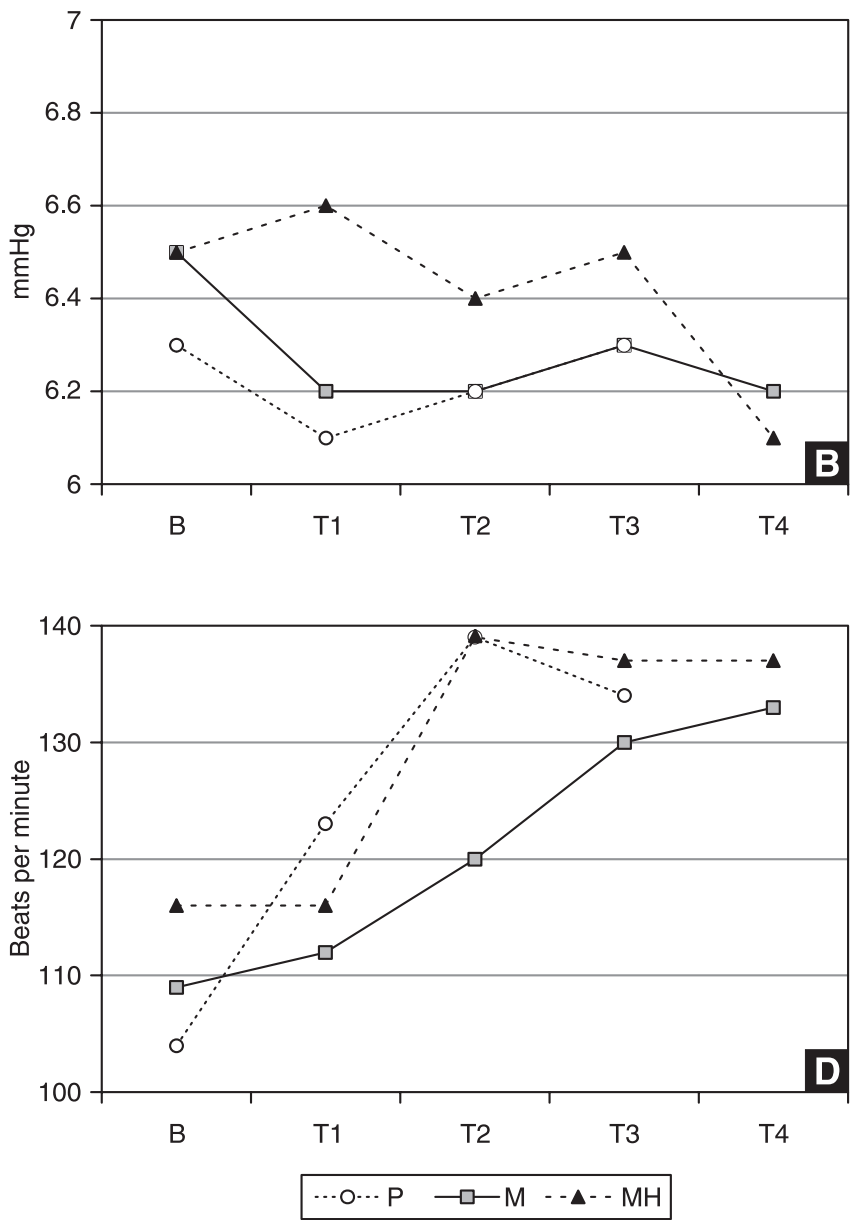

GRAPH 1 - Vital signs means observed in placebo (P), midazolam (M) and midazolam associated to hidroxyzyne (MH) groups, according to baseline (B), at the beginning of dental treatment (T1), after 15 minutes (T2), after 30 minutes (T3) and after 45 minutes (T4). A - systolic blood pressure, B - diastolic blood pressure, $\mathbf{C}$ - breathing rate, $\mathbf{D}$ - heart rate. 
Lima ARA, Costa LRRS, Costa PSS. A randomized, controlled, crossover trial of oral midazolam and hydroxyzine for pediatric dental sedation. Pesqui Odontol Bras 2003;17(3):206-11
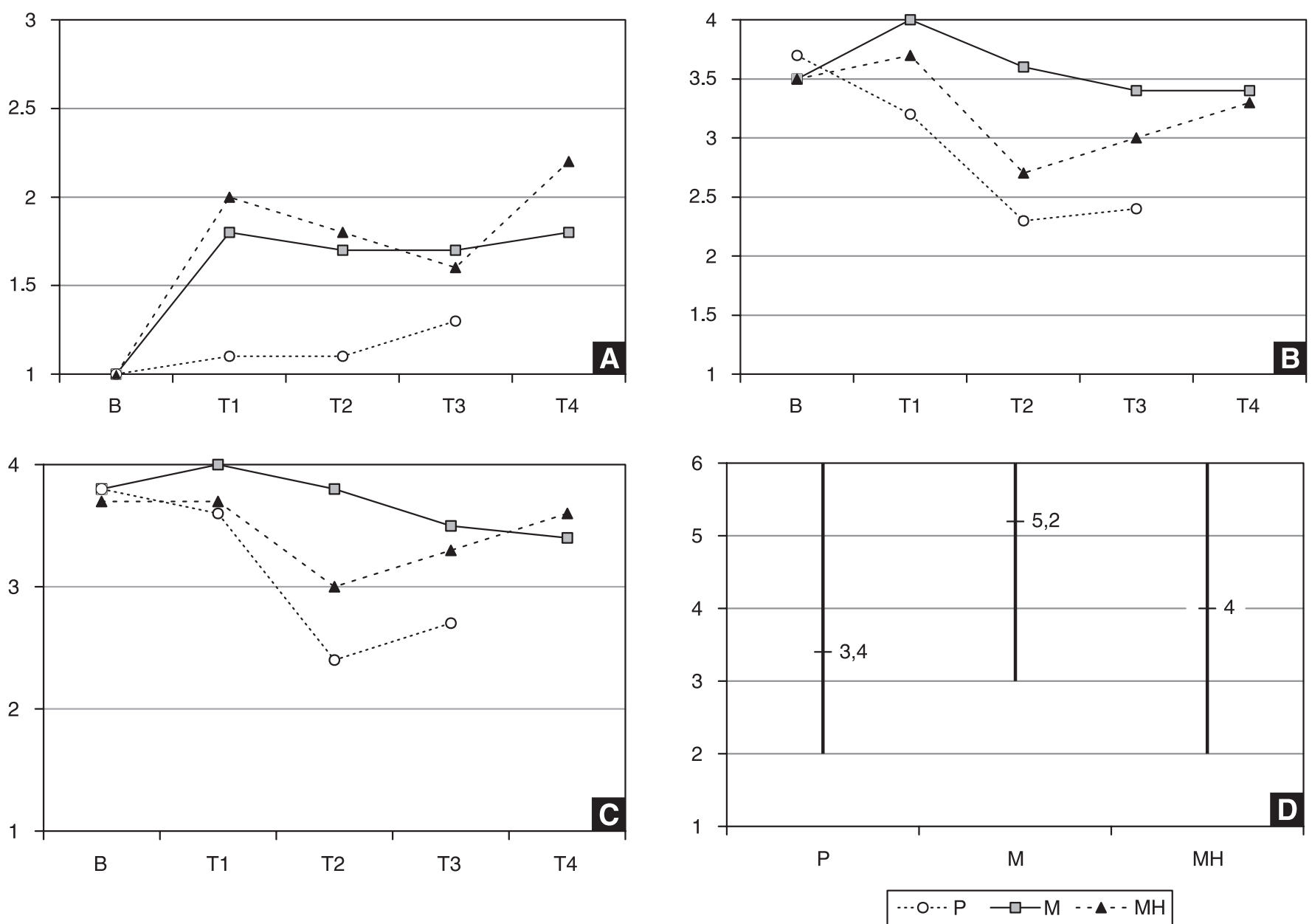

GRAPH 2 - Behavior scores means observed in placebo (P), midazolam (M) and midazolam associated to hidroxyzyne $(\mathrm{MH})$ groups, according to baseline (B), at the beginning of dental treatment (T1), after 15 minutes (T2), after 30 minutes (T3) and after 45 minutes (T4). A - consciousness, B - crying, C - movement, D - overall behavior, according to Houpt et al. ${ }^{13}$ (for additional scores details, go to Material and Methods).

children asleep (A) at the beginning of the dental session than did group $\mathrm{P}(\mathrm{p}=0.018)$, although this difference was not true for group $M$ related to group $P(p=0.059)$. Crying registered at $15 \mathrm{~min}-$ utes of treatment was better in group $M$ than in group $\mathrm{MH}(\mathrm{p}=0.028)$ and group $\mathrm{P}(\mathrm{p}=0.025)$, as higher scores were related to less crying. Movement at 15 minute intervals had lower scores in group $\mathrm{P}$ than in group $\mathrm{M}(\mathrm{p}=0.018)$.

Comparisons of group behavior showed statistically significant differences only in groups $M$ and $\mathrm{MH}$, regarding consciousness. In group $\mathrm{M}$, consciousness decreased in the first 30 minutes of treatment $(\mathrm{p}=0.014)$, and in group MH more drowsy patterns were observed in the first 45 minute periods ( $p=0.018)$, when compared to baseline data.

Overall behavior analysis showed that group $M$ was significantly better than group $\mathrm{P}(\mathrm{p}=0.011)$ and group $\mathrm{MH}(\mathrm{p}=0.022)(\mathrm{Graph} 2)$. Since no serious adverse events were observed in the groups, the success rate for each group based solely on overall behavior scores 5 and 6 was $7.7 \%(\mathrm{P})$, $77.0 \%(\mathrm{M})$ and $30.8 \%(\mathrm{MH})$.

\section{DISCUSSION}

The results of this double-blind, randomized, crossover study indicated that midazolam sedations represent a safe pharmacological technique for behavior control in pediatric dentistry, although its effectiveness remains questionable.

Some methodological explanations are necessary. While a small number of patients participated in this study, the crossover design ensured that patients could be compared to each other. However, this sample is compatible with Brazilian 
Lima ARA, Costa LRRS, Costa PSS. A randomized, controlled, crossover trial of oral midazolam and hydroxyzine for pediatric dental sedation. Pesqui Odontol Bras 2003;17(3):206-11

statistics $^{4}$, where approximately $3.6 \%$ of a 3,500 children population needed sedation.

A negative placebo control group was used due to the fact that, in Brazil, dentists control their patients' behavior by non-pharmacological techniques only. Indeed, children's parents were informed that the use of a placebo would occur.

There is some controversy about the interval required for the dental procedure after oral administration of midazolam, which can vary from 10, 15, 20 or 30 minutes $^{9}$. In our study we chose 30 minutes because of the use of hydroxyzine. If we had considered midazolam alone this interval could be reduced, but this would not allow a double-blind study.

Our results showed that dental appointments were longer than those related to other midazolam studies $^{5,19,26}$. Even in placebo sessions almost one hour of treatment was observed. This could be explained by the fact that we rarely abandoned some treatment, in many cases using physical restraint in order do finish the procedure.

Our findings in vital signs confirmed the safety of midazolam. Breathing rate didn't generally surpass normal values for the age bracket under study, that is, less than 40 breaths per minute, for one to five year old children ${ }^{1}$. In all groups, heart rate sometimes exceeded the normal 130 beats per minute $(\mathrm{bpm})$ limit $^{2}$. However, it is known that these levels can go up to $170 \mathrm{bpm}$ during crying, and that only persistent tachycardia would require an investigation $^{2}$. Indeed, we should recognize that the high heart rates are compatible with anxiety states.

By observing behavioral score figures, it can be noted that consciousness, movement and crying tended to worsen over the course of dental appointments. In addition, only sleeping was really affected by $\mathrm{M}$ and $\mathrm{MH}$. This means that the drugs weren't effective in eliminating extremely bad behavior, that is, all hysterical crying and violent movement.

In view of these behavioral parameters, it was possible to verify that this research was limited, in that the 15-minute time interval between evaluations did not allow the investigators to have a more comprehensive view of the entire session. In fact, the data could even mask the real situation, and present either a more favorable or unfavorable result, depending on the moment the evaluations were carried out ${ }^{22}$. On the other hand, in order to evaluate the behavior of these children during den- tal treatment under sedation, Fraone et $a .^{8}$ decided to film the patients to overcome this bias.

In terms of overall behavior, there were statistically significant differences in the scores between groups $M$ versus $P$, and $M$ versus $M H$, and they don't agree with those in Wilson's findings ${ }^{25}$, who found that the association of hydroxyzine with midazolam was useful. However, the table proposed ${ }^{13}$ does not envisage dental treatment carried out under physical restraint, and in our study this method had to be used in a few instances.

Based on our results, if we consider that hydroxyzine did not potentiate the effect of midazolam, the fact that group $\mathrm{MH}$ had a lower dose of midazolam probably led to worse results than those observed in group $\mathrm{M}^{19}$. Thus, bearing in mind that polypharmacy must be avoided due to known adverse reactions, the association hydroxyzine-midazolam brings no benefits to dental sedation, although a study affirms that there is no significant adverse interaction between midazolam and hydroxyzine ${ }^{19}$.

There was an improvement in behavior, however, when this benzodiazepine was used. Success rates for midazolam pedodontic sedation were similar to those found in another study ${ }^{20}$.

The data in this paper are not meant to encourage dental surgeons to perform routine dental procedures under sedation, in the dental office. Much to the contrary, the aim of this paper is to stimulate more research with a larger patient sample so that other drugs can be studied in order to establish the feasibility of pharmacological sedation in pediatric dentistry.

\section{CONCLUSIONS}

The differences found in overall behavior scores between the midazolam $(1.0 \mathrm{mg} / \mathrm{kg})$ group and the others ( $\mathrm{P}$ and $\mathrm{MH}$ ) were statistically significant and clinically relevant. Midazolam showed the best effectiveness rate $(77 \%)$. Upon evaluation of the safety aspect of midazolam and hydroxyzine, both protocols were found to be safe. Even when significant differences were found in some of the physiological parameters, none of the values went beyond normal limits. According to this methodology, no advantages were found in the use of the association of midazolam with hydroxyzine.

\section{ACKNOWLEDGEMENTS}

To CNPq and to FUNAPE/UFG for the researcher grant. 
Lima ARA, Costa LRRS, Costa PSS. A randomized, controlled, crossover trial of oral midazolam and hydroxyzine for pediatric dental sedation. Pesqui Odontol Bras 2003;17(3):206-11

\section{REFERENCES}

1. Behrman RE. Assessment of growth and development. In: Behrman RE, Kliegman RM, Arvin AM. Nelson textbook of pediatrics. $15^{\text {th }}$ ed. Philadelphia: Saunders; 1996. p. 32-41.

2. Behrman RE. Evaluation of the cardiovascular system. In: Behrman RE, Kliegman RM, Arvin AM. Nelson textbook of pediatrics. $15^{\text {th }}$ ed. Philadelphia: Saunders; 1996. p. 1125-43.

3. Collins VJ. Benzodiazepines. In: Collins VJ. Physiologic and pharmacologic bases of anesthesia. Philadelphia: Saunders; 1999. p. 531-5.

4. Dezan CC, Frossard WTG, Walter LRF, Castaneda LCR. O uso da sedação com hidrato de cloral na Odontologia para bebês. Rev Bras Odontol 1994;51:8-11.

5. Downs AT, Dembo J, Ferretti G, Lyons TD, Pelphry A. A comparative study of midazolam to meperidine/promethazine as an IM sedative technique for the pediatric dental patient. ASDC J Dent Child 1997;64:197-200.

6. Erlandsson AL, Bäckman B, Stenström A, Stecksén-Blicks C. Conscious sedation by oral administration of midazolam in paediatric dental treatment. Swed Dent J 2001; 25:97-104.

7. Feld LH, Negus JB, White PF. Oral midazolam preanesthetic medication in pediatric outpatients. Anesthesiology 1990;73:831-4.

8. Fraone G, Wilson S, Casamassimo PS, Weaver J, Pulido AM. The effect of orally administered midazolam on children of three age groups during restorative dental care. Pediatr Dent 1999;21:235-41.

9. Gallardo F, Cornejo G, Borie R. Oral midazolam as premedication for the apprehensive child before dental treatment. J Clin Pediatr Dent 1994;18:123-7.

10. Gilman AG. Histamina, bradicinina e seus antagonistas. In: Gilman AG. As bases farmacológicas da terapêutica. 9a ed. Rio de Janeiro: Guanabara-Koogan; 2001. p. 430-1.

11. Gladney M, Stanley RT, Hendricks SE. Anxiolytic activity of chloral hydrate and hydroxyzine. Pediatr Dent 1994; 16:183-9.

12. Hobbs WR, Rall TW, Verdoorn TA. Hipnóticos e sedativos; etanol. In: Gilman AG. As bases farmacológicas da terapêtica. $9^{a}$ ed. Rio de Janeiro: Guanabara-Koogan; 2001. p. 264-73.

13. Houpt MI, Koenigsberg SR, Weiss NJ, Desjardins PJ. Comparison of chloral hydrate with and without promethazine in the sedation of young children. Pediatr Dent 1985; $7: 41-6$.
14. Hulland SA, Freilich MM, Sàndor GK. Nitrous oxide-oxygen or oral midazolam for pediatric outpatient sedation. Oral Surg Oral Med Oral Pathol Oral Radiol Endod 2002; 93:643-6.

15. Krafft TC, Krämer N, Kunzelmann KH, Hickel R. Experience with midazolam as sedative in the dental treatment of uncooperative children. ASDC J Dent Child 1993; 60:295-9.

16. Kupietzky A, Holan G, Shapira J. Intranasal midazolam better at affecting amnesia after sedation than oral hydroxyzine: a pilot study. Pediatr Dent 1996;18:32-4.

17. Marshall WR, Weaver BD, McCutcheon P. A study of the effectiveness of oral midazolam as a dental pre-operative sedative and hypnotic. Spec Care Dentist 1999;19:259-66.

18. Mosby's Drug Consult, 2002. Midazolam hydrocloride. $11^{\text {th }}$ ed. St Louis: Mosby; 2001.

19. Nathan JE, Vargas KG. Oral midazolam with and without meperidine for management of the difficult young pediatric dental patient: a retrospective study. Pediatr Dent 2002; 24:129-38.

20. Primosch RE, Bender F. Factors associated with administration route when using midazolam for pediatric conscious sedation. ASDC J Dent Child 2001;68:233-8.

21. Ram D, Mamber E, Chosack A, Fuks AB. The effect of metoclopramida and hydroxyzine in sedation of infants undergoing dental treatment. ASDC J Dent Child 1999; 66:49-52.

22. Romano AJM. Uso intranasal do midazolam em sedação odontopediátrica: relato de um caso clínico. [Monografia de Especialização]. Goiânia: Faculdade de Odontologia da UFG; 1998.

23. Shapira J, Holan G, Botzer E, Kupieztky A, Tal E, Fuks AB. The effectiveness of midazolam and hydroxyzine as sedative agents for young pediatric dental patients. ASDC J Dent Child 1996;63:421-5.

24. Singh N, Pandey RK, Saksena AK. A comparative evaluation of oral midazolam with other sedatives as premedication in pediatric dentistry. J Clin Pediatr Dent 2002;26:161-4.

25. Wilson S. Pharmacologic behavior management for pediatric dental treatment. Pediatr Clin North Am 2000; 47:1159-75.

26. Wilson S, Easton J, Lamb K, Orchardson R, Cassamassino $\mathrm{P}$. A retrospective study of chloral hydrate, meperidine, hydroxyzine, and midazolam regimens used to sedate children for dental care. Pediatr Dent 2000;22:107-12.
Recebido para publicação em 30/04/03 Enviado para reformulação em 16/06/03 Aceito para publicação em 04/08/03 